\title{
ИСПОЛЬЗОВАНИЕ ГИПЕРТЕКСТОВОЙ ТЕХНОЛОГИИ В АНАЛИЗЕ СООТВЕТСТВИЯ ОТЧЕТНОСТИ ОРГАНИЗАЦИИ СТАНДАРТАМ GRI STANDARDS
}

\author{
(c) 2019 Басова Мария Михайловна \\ кандидат экономических наук \\ доцент Департамента учета, анализа и аудита \\ Финансовый университет при Правительстве Российской Федерации, Россия, Москва \\ E-mail: MMBasova@fa.ru
}

В статье обосновывается целесообразность использования систем автоматизации при разработке и анализе нефинансовой отчетности предприятий, которые позволят кардинально изменить способ просмотра и восприятия информации, внося тем самым возможность оперативного ее просмотра и актуализации. Показывается, что отчетность об устойчивом развитии должна характеризоваться высоким соответствием стандарту GRI STANDARDS.

Ключевые слова: нефинансовая отчетность; отчетность об устойчивом развитии организации; гипертекстовая технология; модульная структура; стейкхолдеры; Глобальная Инициатива по Отчётности; стандарт GRI STANDARDS; «Указатели соответствия GRI целям устойчивого развития ООН и РФ».

Сегодня концепция устойчивого развития, которая исходит из необходимости обеспечивать мировой баланс между решением социально-экономических проблем и сохранением окружающей среды, стала наиболее известной моделью будущего мировой цивилизации. Отчет об устойчивом развитии (далее Отчет) - это отчет о деятельности компании, который раскрывает информацию в областях экологии, экономики, корпоративного управления и социальной сферы.

«Большинство российских компаний стремятся к повышению информированности инвесторов, кредитных организаций, поставщиков и покупателей об основных аспектах своей деятельности путем предоставления достоверной, содержательной и оперативной информации. Наряду с обязательной отчетностью (бухгалтерской, налоговой, статистической, годового отчета акционерных обществ) значительное количество российских и зарубежных компаний составляют и предоставляют широкому кругу заинтересованных сторон и другие формы отчетности» [4].

«Отчетность компании отражает культуру ведения бизнеса. Значение совершенствования отчетности обусловлено тем, что она привносит изменения и в практику управления компанией, т.е. имеется взаимосвязь между отчетностью и управлением бизнесом: с одной стороны, чем

качественнее отчетность, тем эффективнее управление; с другой - чем эффективнее бизнес, тем качественнее отчетность. Наличие интегрированной отчетности обеспечит более устойчивое финансово-экономическое состояние не только отдельных компаний, но и экономики страны в целом» [8].

На протяжении последних лет ряд крупнейших российских компаний наряду с годовым финансовым отчетом представляют и нефинансовую отчетность, которая составляется по международным стандартам GRI. Многие крупные организации ежегодно публикуют свои отчеты в области устойчивого развития с целью документального подтверждения приверженности принципам устойчивого развития. «К настоящему времени сложилась группа российских компаний - лидеров в области подготовки отчетов об устойчивом развитии, накопивших достаточный опыт раскрытия информации нефинансового характера в корпоративной отчетности» [6].

Глобальный совет по стандартам в области устойчивого развития («The Global Sustainability Standards Board» (GSSB) 19 апреля 2016 года анонсировал проект серии стандартов GRI по отчетности в области устойчивого развития для общественного обсуждения заинтересованными сторонами в различных регионах мира. Общественное обсуждение проходило до 17 июля 2016 года [11]. Период общественных слушаний, 
который закончился 17 июля, дал всем заинтересованным сторонам возможность просмотреть и оставить отзыв касательно новой модульной структуры, а также внести свой вклад в улучшение проекта Стандартов. Многие оставили свой отзыв на специальной интернет - площадке, а другие на 1 из 15 консультативных семинаров, которые проводились в 13 странах мира.

После всех обсуждений Глобальная Инициатива по Отчётности (GRI) опубликовала новые стандарты, которые имеют модульную структуру GRI STANDARDS и состоят из трёх универсальных стандартов и 33 тематических. Одной из причин такого разделения является то обстоятельство, что подобное деление GRI в случае необходимости позволит в дальнейшем вносить необходимые изменения в каждый из предложенных стандартов по отдельности, не затрагивая общего обновления всех стандартов; оперативно вносить уточнения отдельных понятий стандарта; устранять ненужное дублирование представляемой в отчетности информации, проводя четкую грань, что необходимо, а что желательно раскрывать. C 1 января 2018 г. GRI STANDARDS рекомендованы к исполнению для отчетов.

В целом, отчетность об устойчивом развитии должна характеризоваться высоким соответствием стандарту GRI Standards. Компании должны приводить подробную статистику по экономическим, экологическим и по социальным аспектам, отражать операционную деятельность и представлять данные в соответствии с информационными потребностями стейкхолдеров. С этой целью возникает необходимость проведения детального анализа в рамках этих аспектов.

Целью проведения такого анализа является определения уровня соответствия отчета представленного компанией стандарту GRI Standards, а также выявление сильных и слабых сторон отчета с позиции раскрытия информации по стандарту. В приложении к нефинансовой отчетности, должна приводится таблица «Указатели соответствия GRI целям устойчивого развития ООН и РФ», которая показывает, насколько каждый из показателей раскрыт и указывает на страницу отчета (или раздел в целом), на которой каждый из элементов раскрывается.

Фрагмент таблицы «Указатели соответствия GRI целям устойчивого развития ООН и РФ» приведен на рисунке 1.

По каждому из рассматриваемых элементов аналитиком дается комментарий, качественно характеризующий уровень раскрытия, а также сильные и слабые стороны представленной информации. Каждый аналитик пользуется своей методикой оценки уровня соответствия. Представим один из вариантов. В основу методики проведения анализа соответствия отчетности

\begin{tabular}{|c|c|c|c|}
\hline Стандарт GRI & Показатели & Разделы Отчета/или ссылки & $\begin{array}{r}\text { Цели ООН } \\
\text { в области } \\
\text { устойчивого } \\
\text { развития }\end{array}$ \\
\hline \multicolumn{4}{|c|}{ GRI 101: Принципы 2016} \\
\hline \multicolumn{4}{|c|}{ СТАНДАРТНЫЕ ЭЛЕМЕНТЫ } \\
\hline \multirow{8}{*}{$\begin{array}{l}\text { GRI 102: } \\
\text { Стандартные } \\
\text { элементы } 2016\end{array}$} & 102-1 Название организации & О Корпорации/Общий обзор & - \\
\hline & 102-2 Активы, бренды, продукты и услуги & $\begin{array}{l}\text { О Корпорации/Общций обзор, Политика } \\
\text { ответственного инвестирования }\end{array}$ & - \\
\hline & 102-3 Расположение шта6-квартиры организации & О Корпорации/Общий обзор & - \\
\hline & $\begin{array}{l}102-4 \text { Расположение основной деятельности орга- } \\
\text { низации }\end{array}$ & О Корпорации/Общий обзор & $\cdot$ \\
\hline & $\begin{array}{l}\text { 102-5 Характер со6ственности и организацион- } \\
\text { но-правовая форма }\end{array}$ & О Корпорации/Общий обзор & - \\
\hline & 102-6 Рынки, на которых работает организация & O Корпорации & - \\
\hline & 102-7 Масшта6 организации & Ключевые показатели & - \\
\hline & $\begin{array}{l}\text { 102-8 Информация о сотрудниках и других работ- } \\
\text { никах }\end{array}$ & $\begin{array}{l}\text { Ключевые показатели, Управление } \\
\text { персоналом, Консолидированные данные }\end{array}$ & 8 \\
\hline
\end{tabular}

Рисунок 1. Фрагмент таблицы «Указатели соответствия GRI целям устойчивого развития ООН и РФ» [12] 
организации стандартам GRI Standards, может быть заложен следующий алгоритм. Если показатель полностью соответствует стандарту, то может быть поставлена оценка 10 , если частично, то -5 , если вовсе не освещен в отчетности, соответственно 0. Таким образом, если отчетность организации полностью раскрыта согласно стандарту, то будет выставлена максимальная суммарная оценка. В противном случае, аналитик должен дать качественную и количественную оценку нераскрытых или частично раскрытых показателей и сформулировать соответствующие рекомендации лицам, ответственным за разработку нефинансовой отчетности.

Как показывает практика, анализ полноты и соответствия отчетности стандартам GRI Standards очень трудоемкий процесс, для которого характерно многократное обращение к нефинансовому отчету, возникает сложность ориентирования в нефинансовом отчете из-за большого количества страниц. Уходит много времени, чтобы найти необходимый раздел и внести в него необходимые коррективы.

Для облегчения данного процесса, по нашему мнению, необходим переход к концепции автоматически поддерживаемых связей между различными фрагментами информации, так называемой гипертекстовой технологии. В электронном тексте таблицы стандартных элементов GRI в качестве гиперссылок могут выступать указатели на конкретный раздел нефинансовой отчетности или определенную страницу.

По данным нефинансовой отчетности за 2017 год, представленной на сайте российского союза промышленников и предпринимателей [13], было проанализировано 57 отчетов об устойчивом развитии организаций на предмет использования гипертекстовой технологии при разработке таблицы «Указатели соответствия GRI целям устойчивого развития» (Таблицы стандартных элементов GRI). Результаты исследования представлены в таблице 1.

Данные таблицы 1 свидетельствуют, что при разработке таблицы стандартных элементов GRI гипертекстовую технологию не использует ни одна организация. Только восемь организаций, таких как: ПАО «ФСК ЕЭС», АО «Техснабэкспорт», АО «ТВЭЛ», АО «Атомэнергомаш», ПАО «МРСК», АО «Уральский электрохимический комбинат», ПАО «ГМК «Норильский никель», ПАО «Полюс» И ПАО «Мобильные ТелеСистемы» приводят ссылки на соответствующие разделы отчетности, но отсутствие ссылки на возврат в головное меню из Отчета делает процесс его изучения и анализа на предмет соответствия стандартам не совсем удобным.

Для создания сложных документов, их структурирования и быстрого поиска информации много возможностей предоставляют современные компьютерные средства. В настоящее время можно легко создать информационную сеть, в которой установлены такие связи внутри одного документа и между документами. При этом стоит заметить, что хороший Отчет должен иметь четкую, логичную и легко воспринимаемую структуру с выделением глав, разделов и подразделов.

Перевод нефинансовой отчетности предприятий в форму гипертекстовой технологии, основан на преобразовании текста из линейной в иерархическую форму. По сравнению с представлением информации в формате обычного

Таблица 1. Уровень автоматизации Таблицы стандартных элементов GRI

\begin{tabular}{|l|c|c|c|c|}
\hline \multirow{2}{*}{$\begin{array}{c}\text { Отраслевая } \\
\text { принадлежность }\end{array}$} & \multirow{2}{*}{ Всего отчетов } & В т.ч. наличие Таблицы стандартных элементов GRI \\
\cline { 3 - 5 } & & \multirow{2}{*}{ Отсутствует } & \multicolumn{2}{|c|}{ Степень автоматизации } \\
\cline { 3 - 5 } & & 1 & 8 & 0 \\
\hline Нефтегазовый сектор & 9 & 1 & 10 & 5 \\
\hline Энергетический сектор & 16 & 0 & 1 & 0 \\
\hline Деревообрабатывающая & 1 & 2 & 6 & 0 \\
\hline Химическая, нефтехимическая & 8 & 5 & 6 & 2 \\
\hline Металлургическая & 13 & 1 & 1 & 0 \\
\hline Производство мащин & 2 & 3 & 1 & 0 \\
\hline Производство пищевых & 4 & 0 & 3 & 8 \\
\hline Телекоммуникационная & 4 & 13 & 36 & \\
\hline итого & 57 & & & \\
\hline
\end{tabular}

Составлено автором 
нефинансового отчета использование гипертекстовой технологии позволяет кардинально изменить способ просмотра и восприятия информации, внося тем самым возможность оперативной ее актуализации.

Гипертексты позволяют давать наглядный обзор раскрываемой в нефинансовом отчете информации, сделать стандарты более удобными в навигации. В тексте выделяются особые поля-ссылки (гиперссылки), которые могут «сразу» привести заинтересованные стороны к нужным главам/темам, рисункам, описаниям.

Новая модульная структура, представленная в форме гипертекста, позволит подстраиваться под конкретную отрасль, что даст компаниям возможность создавать отчеты “по своей мерке”, легко обновлять их и, в случае необходимости, добавлять новые пункты. Так например, пользователи стандартов должны быть готовы к тому, что стандарты могут меняться. Неоценимую помощь и в этом поможет гипертекстовая технология, которая позволит оперативно перестроить любой отчет в соответствии с новыми требованиями.

Представим технологию процесса перевода отчета об устойчивом развитии организации в форму гипертекста. Основным документом (главным меню) будем считать таблицу «Указатели соответствия GRI целям устойчивого развития ООН и РФ».

Шаг 1. Структурирование Отчета. Структурирование - это умение выделить главные мысли и выстроить последовательность их изложения и уровень детализации. Для этого необходимо выделить основные темы, потом удалить не имеющие отношение к цели документа, определить тип высказываний (описание целей, задач, проектов, последовательность фактов и формат подачи цифр) и после этого изложить конкретизировать информацию.

Структурно нефинансовая отчетность включает ключевые показатели деятельности компании, данные о качестве корпоративного управления; кадровом составе предприятия и методах управления им; о качестве продукции и услуг; вкладе предприятия в охрану окружающей среды, поддержке местных сообществ, воздействиях компании на общество. Первоначально текст отчета должен быть разбит на отдельные главы/ разделы, которые должны соответствовать разделам таблицы «Указатели соответствия GRI целям устойчивого развития ООН и РФ» Далее текст отчета об устойчивом развитии организации необходимо преобразовать из линейной формы в гипертекстовую (сетевую), для чего можно представить графическую модель, при необходимости можно дополнить своими страницами связи; каждой странице можно присвоить свое имя; выделить ключевые слова и предусмотреть ключевое слово возврата по сети.

Шаг 2. Структурирование таблицы. В таблице «Указатели соответствия GRI целям устойчивого развития ООН и РФ» необходимо выделить ключевые слова (гипертекстовые ссылки), которые в дальнейшем будут связаны с существующими темами (разделами) отчета об устойчивом развитии организации.

Шаг 3. Связать таблицу с Отчетом. Далее требуется представить некоторый основной путь чтения таблицы «Указатели соответствия GRI целям устойчивого развития ООН и РФ» «с выходом» на соответствующие разделы нефинансового отчета и расставить, соответственно, поля-ссылки, ведущие заинтересованное лицо от указанной выше таблицы к соответствующему разделу Отчета по этому основному пути. Например, если заинтересованное лицо интересует информация по ключевым факторам и рискам, то он по ссылке из основного меню таблицы «Указатели соответствия GRI целям устойчивого развития ООН и РФ» должен перейти к разделу Отчета «Управление рисками». Таким образом, доступ к фрагментам осуществляется из главного документа - таблицы «Указатели соответствия GRI целям устойчивого развития ОOH и PФ» с помощью гиперссылок, указывающих путь к местоположению данных основного текста.

Шаг 4. Программная реализация гипертекстовой технологии. Для перехода к любому включенному в документ фрагмент Отчета в таблице «Указатели соответствия GRI целям устойчивого развития ООН и РФ» в результате использования соответствующих программных средств (например, MS WORD) появятся слова-ссылки, которые позволят перейти к требуемым темам (разделам) нефинансового отчета (рисунок 2).

Шаг 5. Корректировка структуры отчета в случае необходимости (например, в связи перехода к новым Стандартам GRI). На этом этапе анализируется новая структура отчета, сравнивается с существующей, вносятся необходимые изменения и проводится аналогичный комплекс работ (переход на шаг 1).

Использование гипертекстовой технологии 


\section{УК̈АЗАТЕЛЬ СОДЕРЖАНИЯ GRI STANDARDS}

\begin{tabular}{|c|c|c|c|}
\hline Стандарт GRI & Показатель & Ссылка & Исключенная информация \\
\hline \multicolumn{4}{|c|}{ GRI 101: Принципы 2016} \\
\hline \multicolumn{4}{|l|}{ Стандартные элементы } \\
\hline \multirow[t]{2}{*}{$\begin{array}{l}\text { GRI 102: Стандартные } \\
\text { элементы } 2016\end{array}$} & $\begin{array}{l}\text { 102-1 Название } \\
\text { организации }\end{array}$ & "Ссылка", & \\
\hline & $\begin{array}{l}\text { 102-2 Активы, бренды, } \\
\text { продукты и услуги }\end{array}$ & "Ссылка", & \\
\hline
\end{tabular}

Рисунок 2. Пример указателя содержания GRI STANDARDS [12]

позволит организациям предоставлять более последовательную, высококачественную отчетность в области устойчивого развития и поможет подотчетным организациям плавно переходить к новым Стандартам GRI (в случае их появления).

Практическая значимость перехода на гипертекстовую технологию заключается в возможности использования ее основных положений:

- специалистами и руководителями фирм при разработке стратегий развития компаний;

- для разработки мероприятий по повышению качества выполнения отчетов;

- стейкхолдерами для оценки стратегического позиционирования компании в области устойчивого развития;

- при подготовке новой редакции стандартов GRI.

Среди основных тенденций оформления нефинансовой отчётности важно отметить ее выход за рамки отчёта об устойчивом развитии в сторону диджитализации. Скорость и объемы современных информационных потоков устанавливают свои правила, поэтому многие организации предпочитают уделять внимание отчётам и статистике, доступным онлайн в режиме реального времени и работе со своими сайтами в целом.

Текстовый формат изложения, даже с обилием диаграмм и графиков, все чаще уступает место инфографике. Безусловно, если говорить о представлении финансовой информации, использование графиков и диаграмм всегда будет уместно, однако не стоит ограничиваться только этим. Для разных целевых аудиторий могут быть уместны совершенно разные формы представления информации: инфографика, скетчи, видео.

Автоматизация нефинансовой отчетности позволит обеспечить формирование достоверной как финансовой, так и нефинансовой информации, снизить временные и трудовые затраты на подготовку и анализ отчётности и повысить оперативность ее формирования и представления пользователям.

\section{Библиографический список}

1. Балдин, К.В. Информационные системы в экономике / К.В. Балдин.- М.: ИНФРА-М, 2018. - 224 с.

2. Бариленко В.И. Информационно-аналитическое обеспечение устойчивого развития экономических субъектов: монография / под ред. проф. О.В. Ефимовой; В.И. Бариленко, О.В. Ефимова, Е.В. Никифорова и др..М.: Издательство «Русайнс», 2015. 160 с.

3. Басова М.М. Анализ социальных аспектов промышленных предприятий // Интернет-журнал «НАУКОВЕДЕНИЕ» Том 7, No2(2015) http://naukovedenie.ru/PDF/59EVN215.pdf (доступ свободный). Загл. с экрана. Яз. рус., англ.DOI: 10.15862/59EVN215.

4. Басова М.М. Содержательный анализ нефинансовой отчетности российских компаний в области устойчивого развития//Вестник СамГУПС.-2016. -№ 4 (34). -С. 52-56.

5. Басова М.М. Особенности составления нефинансовой отчетности в социально ориентированных некоммерческих организациях // Вестник Московского университета им. С.Ю. Витте. Серия 1: Экономика и управление. 2017. № 3 (22). С. 50-53. 
6. Ефимова О.В. Формирование информации о финансовом капитале и ее анализ в интегрированной отчетности / В сборнике: Учетно-аналитическое обеспечение - информационная основа экономической безопасности хозяйствующих субъектов Межвузовский сборник научных трудов и результатов совместных научно-исследовательских проектов: в 2-х частях. Москва, 2017. С. 126-131.

7. Завизена Н.С., Теплицкий А.И., Семериков С.А., Каращук А.М. Построение гипертекстовых систем на основе Web-технологий. - Кривой Рог: КГПИ, 1999.- 42 с.

8. Когденко В.Г., Мельник М.В. Интегрированная отчетность: вопросы формирования и анализа // Международный бухгалтерский учет. 2014. № 10 (304). С. 2-15.

9. Уткин, В.Б. Информационные системы в экономике / В.Б. Уткин, К. В. Балдин. - М.: Academia, 2018. - 288 с.

10. Черников, Б.В. Информационные технологии управления / Б.В. Черников.- М.: Инфра-М, Форум, 2017.368 c.

11. Официальный сайт Группы Компаний Да-Стратегия [Электронный ресурс] -URL: http://da-strateg.ru

12. https://www.globalreporting.org

13. Официальный сайт Российского союза промышленников и предпринимателей [Электронный ресурс] URL: http://www.rspp.ru 